\title{
Plasmonics: Future and Challenges
}

\author{
Vincenzo Giannini ${ }^{1,2 *}$ \\ ${ }^{1}$ Instituto de Estructura de la Materia (IEM), Madrid, Spain, ${ }^{2}$ Consejo Superior de Investigaciones Científicas (CSIC), Madrid, \\ Spain
}

Keywords: plasmonics, surface-enhanced Raman scattering, nanophotonic, electromagenetism, condensed matter, nanoantenas, Mie scattering, 2D polaritonics

It seems clear that the next big technological advance is inexorably linked with our ability to manipulate light at the nanoscale. One major task among many is to invert the stagnant performance of microprocessors during the last years. Shifting from using electronic to photonic systems could have a disruptive impact on the next computational and communication technologies as well as presenting new avenues in fundamental research. Of all photonics research areas, plasmonics is possibly the most promising route toward this goal.

Plasmonics (see Figure 1) is historically related to the study of how light interacts with the electrons of metal nanoparticles (Giannini et al., 2011). Artists trying to color glass started such studies empirically a long time ago, but the first rigorous description using electromagnetism came with the work of Mie, Lorenz, and Debye during the early 20th century (Lorenz, 1890; Mie, 1908; Debye, 1909). A deep interpretation of this mixed electron-photon excitation was given only several years later in 1952, thanks to the beautiful work of Bohm and Pines (1952) that realized the importance of long-range interactions and collective electron effects, settling the theoretical basis in the framework of quantum many-body physics. The next important progress in the field came as a series of seminal works on surface plasmon polaritons in the 60-70 s led by Teng and Stern (1967), Otto (1968), and Kretschmann and Rather (1968), followed by the discovery of the surface-enhanced Raman scattering by Fleischmann et al. (1974).

Nowadays plasmonics has become a shining and mature field, boosted by the technological advances in nanofabrication, laser sources, and computational power, which have contributed to keep

\section{OPEN ACCESS}

Edited and reviewed by: Costantino De Angelis,

University of Brescia, Italy

${ }^{*}$ Correspondence: Vincenzo Giannini v.giannini@csic.es

Specialty section: This article was submitted to Plasmonics,

a section of the journal

Frontiers in Photonics

Received: 26 October 2020 Accepted: 02 November 2020 Published: 30 November 2020

Citation:

Giannini V (2020) Plasmonics: Future and Challenges.

Front. Photonics 1:621510. doi: 10.3389/fphot.2020.621510

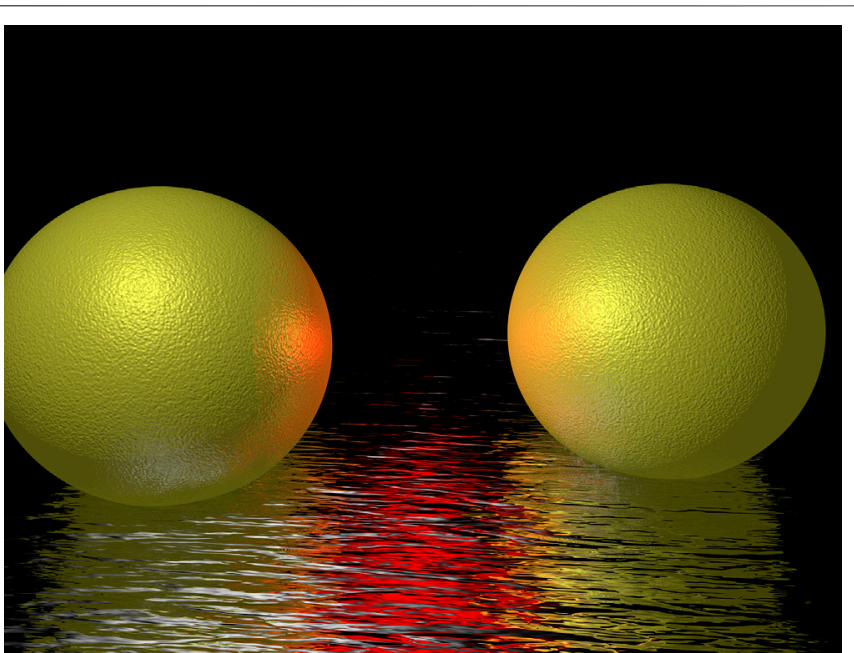

FIGURE 1 | Plasmonic nanoparticle artistic image. 
the discipline in a forefront position. It has made an indelible contribution to theoretical and experimental advances in photonics, condensed matter and chemistry, as well as providing a crucial bridge from fundamental science to applications.

This brings us to the grand challenges that this field is facing today. Plasmonics in the next years aims to control light at the nanoscale with precision and low losses. In order to do so, we need to push the localization of light to unprecedented limits while preserving its propagative nature. $2 \mathrm{D}$ natural hyperbolic materials and graphene present extremely promising candidates toward this goal. Success in this area will herald a plethora of new physics at the atomic and molecular scale. Simultaneously, for the development of nanophotonic circuits, we should aim to keep plasmon propagation robust, which will likely be achieved by advances topological plasmonics. In order to

\section{REFERENCES}

Bohm, D., and Pines, D. (1952). A Collective Description of Electron Interactions: II. Collective vs Individual Particle Aspects of the Interactions. Phys. Rev. 85, 338.

Debye, P. (1909). Der Lichtdruck auf Kugeln von beliebigem Material. Ann. Phys. 30, 57-136. doi:10.1002/andp.19093351103

Fleischmann, M., Hendra, P., and McQuillan, A. (1974). Raman spectra of pyridine adsorbed at a silver electrode. Chem. Phys. Lett. 26, 163-166. doi:10.1016/0009-2614(74)85388-1

Giannini, V., Fernández-Domínguez, A. I., Heck, S. C., and Maier, S. A. (2011). Plasmonic nanoantennas: fundamentals and their use in controlling the radiative properties of nanoemitters. Chem. Rev. 111, 3888-3912. doi:10.1021/cr1002672

Kretschmann, E., and Raether, H. (1968). Radiative decay of nonradiative surface plasmons excited by light. Z. Naturf. A 23, 2135-2136. doi:10.1515/zna-19681247

Lorenz, L. (1890). Lysbevægelser i og uden for en af plane Lysbølger belyst Kugle. Videnskab. Selskab. Skrifter. 6, 1-62. design such plasmonics circuits, important improvements in nanofabrication will need to be made. Finally, to keep up with these experimental advances we will need theoretical models in order to describe the nonlocal and nonlinear physics of such devices. In particular, we will need to care about the quantization of both matter and light at the same time. In combination, all of these exciting advances blaze an exciting path toward a deeper understanding of light-matter interactions.

\section{AUTHOR CONTRIBUTIONS}

The author confirms being the sole contributor of this work and has approved it for publication.

Mie, G. (1908). Beiträge zur optik trüber medien, speziell kolloidaler metallösungen. Ann. Phys. 330, 377-445. doi:10.1002/andp.19083300302

Otto, A. (1968). Excitation of nonradiative surface plasma waves in silver by the method of frustrated total reflection. Z. Phys. 216, 398-410. doi:10.1007/ BF01391532

Teng, Y.-Y., and Stern, E. A. (1967). Plasma radiation from metal grating surfaces. Phys. Rev. Lett. 19, 511. doi:10.1103/PhysRevLett.19.511

Conflict of Interest: The author declares that the research was conducted in the absence of any commercial or financial relationships that could be constructed as a potential conflict of interest.

Copyright (c) 2020 Giannini. This is an open-access article distributed under the terms of the Creative Commons Attribution License (CC BY). The use, distribution or reproduction in other forums is permitted, provided the original author(s) and the copyright owner(s) are credited and that the original publication in this journal is cited, in accordance with accepted academic practice. No use, distribution or reproduction is permitted which does not comply with these terms. 